\title{
A VIVÊNCIA DA GRAVIDEZ DO PRIMEIRO FILHO À LUZ DA PERSPECTIVA PATERNA
}

\author{
Ellen Andrea Bornholdt* \\ Adriana Wagner** \\ Ana Cristina Pontello Staudt ${ }^{* * *}$
}

\section{RESUMO}

Este estudo descreve a vivência do homem na gravidez do seu primeiro filho. Utilizou-se como método o estudo de caso instrumental (Stake, 1994), partindo de entrevistas com cinco homens que estavam à espera do primeiro filho, analisando-as através da análise de conteúdo (Moraes, 1999; Olabuénaga, 1996). Foi realizada uma análise vertical e horizontal dos casos, ressaltando suas idiossincrasias e seus aspectos comuns. Suas experiências variaram desde a percepção da gravidez como um período de transição ao exercício da paternidade ao sentimento de inclusão e participação na gestação. Valores e prioridades foram redimensionados na relação conjugal. A preocupação com a malformação fetal, as adversidades do mundo contemporâneo e o período adolescente são seus maiores temores. A questão financeira apareceu como principal preocupação no exercício da paternidade, seguida do desejo de envolvimento no desenvolvimento dos filhos.

Palavras-chave: gravidez, vivência paterna, primeiro filho

* Doutora em Psicologia pela Universidade del Salvador, Buenos Aires.

** Doutora em Psicologia; Professora da Pontifícia Universidade Católica do Rio Grande do Sul; Coordenadora do Grupo de Pesquisa "Dinâmica das Relaçôes Familiares" (Pontifícia Universidade Católica do Rio Grande do Sul); Bolsista Produtividade CNPq. Orientadora do Trabalho.

*** Mestre em Psicologia Social e da Personalidade pela Pontifícia Universidade Católica do Rio Grande do Sul; Bolsista CNPq. 


\begin{abstract}
THE EXPERIENCE OF PREGNANCY OF THE FIRST CHILD THROUGH THE FATHER'S POINT OF VIEW

This research describes the man's experience while expecting the birth of his first child. The method used was the study of an instrumental case (Stake, 1994), starting with interviews of five men expecting their first child's birth, analyzed through content analysis (Moraes, 1999; Olabuénaga, 1996). Vertical and horizontal analyses of the cases were made, highlighting their idiosyncratic and common aspects. Their experiences varied from a transition period, to a feeling of both inclusion and participation of the pregnancy. Values and priorities were redimensioned on the couple's relationship. Preoccupation with fetal anomalies, contemporary world adversities and the adolescence period are their biggest concerns. Financial issues appear as main worries for the exercise of fatherhood, followed by the desire of getting involved with the child's development.

Keywords: pregnancy, fatherhood experience, first child
\end{abstract}

\title{
1. INTRODUÇÃo
}

Este estudo foca a família no momento vital de ampliação do subsistema conjugal ao parental. Trata-se do nascimento do filho primogênito, período de transição importante na vida do casal que necessita estabelecer novos papéis e relações a fim de integrar um novo membro no grupo familiar. Somam-se à vivência de tal momento evolutivo as mudanças que a família vem passando nos últimos tempos, não só com o estabelecimento de novas configurações, mas, principalmente, no que diz respeito ao exercício de seus papéis (Carter \& McGoldrick, 1995; Musito, 2001).

Apesar da importância desta fase de transição da família, essa é uma etapa ainda pouco estudada desde a perspectiva do pai. Uma consulta realizada em uma importante base de dados referente aos últimos quatro anos (WebScience, 20032006) identificou haver 1740 artigos que abordavam o assunto "a gravidez e a mãe" e apenas 145 artigos que abordavam a "a gravidez e o pai”. Ainda que seja compreensível que a mãe, neste momento do ciclo vital, seja enfaticamente estudada, questiona-se por que as mudanças que ocorrem com o pai, ainda hoje, recebem atenção tão reduzida.

No entanto, a vivência deste período é também bastante intensa para muitos homens. Algumas pesquisas falam inclusive da chamada "Síndrome de Couvade" (Budur, Mathews \& Mathews, 2005; Piccinini, Silva \& Gonçalves, 2004). Esta, tida como uma expressão somática da ansiedade que envolve todo esse processo, 
relaciona-se a diversos fatores emocionais presentes neste período, como uma identificação do pai com a esposa grávida ou até mesmo uma ambivalência em relação à paternidade e ao processo de adaptação a essa nova situação. Estes aspectos podem revelar o sentimento de exclusão, muitas vezes presente neste processo, além do pouco espaço que muitos pais encontram para expressar todas suas angústias e expectativas. Este processo pode acarretar o desenvolvimento de diferentes fantasias nos homens, como o temor de que o bebê traga algum tipo de desestabilização no casamento, já que muitos apontam haver uma diminuição da satisfação conjugal com o decréscimo da vida social e sexual do casal (Hijjawi, 2005; Pacey, 2004; Rodriguez, 2004; Shapiro, 2005).

No entanto, considerando a representação dos papéis masculinos e femininos em nossa cultura, apesar das recentes transformaçôes, é bastante prevalente a manutenção dos estereótipos de gênero que reforçam a dicotomia entre os papéis (Costa, 2000; Fleck, Falcke \& Hackner, 2005; Lewis \& Lamb, 2003; Meler, 2000; Staudt, 2007; Trindade \& Menandro, 2002).

Um exemplo disto é o fato de que muitos pais demonstrem uma maior necessidade de serem os principais provedores financeiros no núcleo familiar, principalmente com a chegada dos filhos. Assim, passam a dar uma atenção aumentada a seu trabalho para oferecer maior segurança financeira à família, demonstrando ser esta uma tarefa ainda creditada principalmente ao homem (Fleck \& Wagner, 2003; Jablonski, 1999; Wagner \& Grzybowski, 2003; Wagner, Hartmann, Oliveira \& Ribeiro, 1999). Entretanto, algumas pesquisas vêm demonstrando haver uma insatisfação dos pais frente a esta realidade, revelando seu desejo de envolverem-se nesta relação muito além do exercício do papel de provedor financeiro (Andrews, Luckey, Bolden, Whiting-Fichling \& Lind, 2004; Bolzan, Galé \& Dudley, 2004; Freitas, Coelho \& Silva, 2007).

Neste sentido, muitos pais contemporâneos encontram-se em uma posição bastante difícil, entre exercer um papel paterno mais tradicional, ainda bastante arraigado no ambiente social e intrafamiliar, ou aventurar-se em uma experiência ainda recente, que é a de ser um pai mais envolvido e menos periférico na relação com seus filhos (Diehl, 2002).

Dessa forma, pode-se pensar que as expectativas e todas as implicações da gravidez são inúmeras, não só para as mulheres, como também para os homens. Neste estudo, buscamos estudar a gravidez do primeiro filho à luz da perspectiva masculina no que diz respeito às questôes relativas à vida do casal e à vivência do período gestacional. Abordamos também os sentimentos relativos à paternidade e às possíveis preocupações destes pais no que diz respeito ao desenvolvimento e futuro do filho. 


\section{Metodologia}

O fenômeno foi estudado a partir de casos individuais, denominados por Stake (1994) de estudo de caso instrumental. Utilizamos entrevistas semiestruturadas realizadas com cinco homens, entre 27 e 35 anos, os quais estavam vivenciando a gravidez de seu primeiro filho. Todos os participantes coabitavam com suas respectivas companheiras há pelo menos um ano. Eles foram nomeados ficticiamente como André, Bernardo, Carlos, Daniel e Eduardo. As entrevistas foram submetidas a uma análise de conteúdo, possibilitando a leitura e interpretação aprofundada daquilo que foi extraído de cada caso (Moraes, 1999; Olabuénaga, 1996). As categorias de análise que emergiram da fala dos sujeitos foram: a passagem da conjugalidade para a parentalidade, os sentimentos de "estar grávido", as perspectivas de futuro em relação à paternidade e ao futuro do filho que estava para nascer. Depois da análise vertical dos casos, que possibilitou conhecer a idiossincrasia da vivência de cada sujeito, foi realizada uma análise horizontal dos cinco casos a fim de mapear aspectos comuns entre eles.

\section{ApresentaÇão dos resultados}

\subsection{ANÁLISE VERTICAL DOS CASOS}

CASO 1 - André, 31 anos, cuja esposa estava grávida de 4 meses.

A passagem da conjugalidade para a parentalidade - André apontou as principais mudanças na relação conjugal, enfatizando o estilo de vida social: "não tem mais aquele embalo, a situação social não é mais aquela que era antes, nossas preocupaçōes agora são outras, é o futuro, o filho, então isso que muda...”. André demonstrou ter percebido que, ainda na gravidez, a criança passa a somar uma nova perspectiva para a relação do casal, na qual o filho entra em cena como personagem principal da família.

Os sentimentos de "estar grávido" - Sobre seus sentimentos durante o processo gestacional, André mencionou sua curiosidade em conhecer o filho e, talvez assim, poder senti-lo mais concretamente, já que não tem a possibilidade de experienciar a presença do feto dentro de si: "estou só mais esperando o momento que vai se aproximando, uma expectativa maior de curiosidade, de saber como é a criança, como não é, como vai ser daqui para adiante, aquela ansiedade...".

Quanto ao sentimento de "estar grávido", respondeu categoricamente que não se sente como tal, referindo-se às diferenças existentes entre homens e mulheres: "Eu não, não tenho nada no meu corpo, ela que tá levando o filho, então eu 
não me sinto grávido, talvez o homem possa vir a sofrer depois, na criação ou logo depois que nasce, por enquanto só tá mudando ela...”. Por outro lado, mencionou perceber algumas mudanças em si, considerando os aspectos emocionais que envolvem esse processo: "sinto só emocionalmente, psicologicamente...".

Perspectiva de futuro em relação à paternidade - Neste aspecto, André mencionou um importante desejo de participar da educação e dos cuidados do filho, dando-lhe afeto: "dar bastante carinho, atenção, amor, tudo que a gente julga necessário para que essa criança nasça com saúde tanto física como psicológica...”.

Suas preocupações quanto ao futuro de sua família, agora com um terceiro membro, dizem respeito, principalmente, à questão econômica. Ainda que tenha o desejo de ser um pai amoroso e envolvido com seu filho, a maior ênfase de seus relatos relaciona-se com a obrigação de prover e manter o sustento da família: "eu só penso em proporcionar o melhor para meu filho e minha família e trabalhar mais para fazer isso...”.

Perspectiva em relação ao futuro do filho - André mencionou o medo de seu bebê não nascer saudável. Ele, inclusive, finalizou a descrição dos seus temores reforçando a idéia de que espera que o seu filho tenha saúde, caracterizando ser esse o seu maior desejo e sua maior preocupação.

Também revelou o temor em relação à inserção do seu filho no mundo, considerando suas adversidades: "a criança vai mudar a vida da gente, porque enquanto ela tá na barriga da mãe a gente fica mais tranqüilo, é um habitat natural dela agora, mas depois que ele vem para fora, daí sim já é uma preocupação maior...”.

\section{Análise Compreensiva do Caso 1:}

Desde o início da entrevista, as verbalizações de André enfatizaram a tranqüilidade e a felicidade de ser uma gravidez desejada e programada. Dessa forma, pode-se perceber que André estava de fato feliz com a gravidez. Entretanto, questionamos o quanto o sujeito expressava seus sentimentos na totalidade, isso é, tanto os positivos quanto negativos, já que, muitas vezes, a presença do homem no processo gestacional é requerida desde que ele não expresse seus sentimentos negativos. Ou seja, de uma maneira geral, há uma pressão social para que o homem seja forte e dê suporte à mulher. Nesse sentido, os sentimentos referentes à ambivalência, à insegurança e até mesmo à raiva durante a gravidez são vistos, ainda hoje, de forma negativa, pois muitos homens sentem-se na obrigação de proteger a esposa/mãe e, conseqüentemente, tendem a inibir seus sentimentos (O’Leary \& Thorwick, 2006).

Outro tema interessante referido por André relaciona-se ao aspecto financeiro na vida do casal. Sua grande exigência de suprir a família financeiramente vai ao encontro de que a noção de principal provedor ainda está, nos dias de hoje, 
associada à figura masculina (Bornholdt, 2006; Burdon, 1998; Chorvat, 2006; Dudova, 2006; Parke, 1998; Trindade \& Menandro, 2002). Ele pretende ser amoroso com o filho, mas enfatizou a obrigação de prover o sustento, talvez, intensificada por uma vivência financeira difícil. Segundo Badinter (1986), desde o momento em que o casamento passou a assegurar a paternidade na família, mediante a criação de filhos legítimos, se instaurou a estrutura social alicerçada no poder do pai. Esse poder, como demonstra André, é representado por aquele que traz dinheiro para casa e é capaz de sustentar o filho (Wagner e cols., 1999).

Quanto aos seus temores mais diretamente ligados ao bebê, a resposta de André foi ao encontro do que diz a literatura: os pais receiam ter um filho com problemas, sendo que a má formação ainda é um fantasma nos dias de hoje. Neste sentido, conforme pesquisa realizada com 35 pais por Piccinini, Silva e Gonçalves (2004), este receio faz parte da preocupação de 68\% dos pais durante a gestação.

André descreveu momentos de envolvimento com a gravidez, tais como quando percebeu o crescimento da barriga e acompanhou os movimentos do bebê. No entanto, achou graça quando questionado sobre "sentir-se grávido". Nesse caso, o sujeito apoiou-se nos fatores biológicos para definir os diferentes papéis a serem desempenhados e a forma de vivenciar a gravidez. Neste sentido, a vivência de André corrobora os achados de recentes pesquisas sobre as relações homem e mulher na família (De Neuter, 2001; Hurstel, 2001). Ainda que estejam sendo redefinidas novas formas de desempenhar os diversos papéis, este não é um processo consolidado. Muitas das tradicionais divisões de papéis se mantêm fortemente e se confundem com as novas formas de relação que se estabelecem na atualidade.

CASO 2 - Bernardo, 27 anos, cuja esposa estava grávida de 9 meses.

A passagem da conjugalidade para a parentalidade - A mudança de perspectiva para Bernardo se deu principalmente nos planos para o futuro do casal e no valor que ele passou a dar à vida: "não sou só eu e ela agora, muda a casa, muda tudo, é uma vida diferente, nossa família agora é eu, ela e ele...”. Outro aspecto referido por ele diz respeito à vida social do casal: "tem uns amigos meus que dizem, como tu consegue! Não sai mais! Mas tem suas compensações, não saio mais como eu gostava, mas vou ter um filho, tu passa a dar valor a outras coisas...”.

Bernardo falou da diminuição da vida sexual e do cansaço decorrente da ansiedade, que muitas vezes resulta em diminuição da tolerância entre eles: “é..., como casal o que modifica bastante, no ultimo mês ou nos últimos dois meses, é a vida sexual, muda bastante, agora no final, principalmente, a gente quase não tem [referindo-se a relações sexuais], isso modifica mesmo...”. 
Os sentimentos de "estar grávido" - Neste aspecto, sua primeira referência foi a de sentir-se “... como se também estivesse grávido...”. Referiu estar vivendo ansiosamente esse momento e se privando de algumas coisas juntamente com a esposa: "olha eu acho que a gente carrega o peso junto com a mãe na barriga, é como se a gente tivesse grávido, a sensação que a gente tem, a ansiedade que a gente fica...".

Relatou este ser o momento de maior tensão em que se encontrava, percebendo em si um aumento da ansiedade e maior irritabilidade. Além disso, mencionou reflexos desse processo em termos de sensações físicas: "uma tensão que reflete no físico, mas fisicamente é só um cansaço, acho que de estresse, é só um cansaço, menos disposição para as coisas como eu tinha, se eu tô em casa parado dá mais vontade de ficar dormindo, do que de ficar acordado...”.

Perspectiva de futuro em relação à paternidade - Bernardo mencionou sentirse com mais responsabilidades, principalmente em relação ao aspecto financeiro. Referiu-se à angústia de trabalhar cada vez mais para proporcionar tudo o que for possível para o filho, sendo essa sua principal motivação para o trabalho no momento: "é uma necessidade de trabalhar mais, tu sabe que a situação não tá fácil para ninguém, então como a responsabilidade depende só de mim, porque ela não tá trabalhando, então não adianta...”. No caso deste casal, a esposa deixou de trabalhar, e a estrutura da casa, do ponto de vista econômico, depende única e exclusivamente de Bernardo, que assume sozinho o papel de provedor. Bernardo falou que nem sempre conseguia participar como gostaria da gravidez de sua esposa, identificando a estrutura profissional como uma interferência negativa durante o processo gestacional: "então eu saio de manhã e só volto à noite, passo muito tempo fora de casa...”.

Outro aspecto levantado por Bernardo relaciona-se à questão afetiva. Ele se cobra uma postura de acordo com a que julga ter recebido de seus pais, ou ainda melhor: "eu vou fazer o possível para ser como meu pai, ou melhor que ele, porque a gente pega as idéias e tenta fazer igual ou melhorar, copiar e adaptar, pelo menos eu vou tentar ser assim...”.

Perspectiva em relação ao futuro do filho - Neste sentido, Bernardo recordouse de aspectos referentes ao seu desenvolvimento enquanto criança e adolescente. Relatou o desejo de que o filho não repetisse alguns de seus comportamentos, como o de não ter aproveitado oportunidades oferecidas por seu pai: "meu pai pagou duas vezes faculdade para mim e eu não tenho faculdade, não concluí nenhum curso...".

Por outro lado, explicitou o desejo de que o filho siga seu modelo durante a adolescência quanto ao fato de ele não ter sido usuário de drogas. Neste momen- 
to, percebe-se uma preocupação de Bernardo frente às adversidades do mundo no qual seu filho vai nascer e que possam estar fora de seu controle.

\section{Análise Compreensiva do Caso 2:}

Bernardo descreveu importantes transformaçôes na vida conjugal, como o aumento da ansiedade, a mudança de valores e a diminuição da vida social e sexual do casal. Esses aspectos corroboram os achados da literatura sobre o aumento do estresse e da ansiedade e a freqüente diminuição da satisfação com a vida de casal como fatores freqüentemente presentes durante o período gestacional e, no entanto, nem sempre abordados (Pacey, 2004; Rodriguez, 2004; Zimmermann, Zimmermann, Zimmermann, Tatsch, \& Santos, 2001). Sendo assim, essas transformações demandam alterações significativas dos papéis familiares, assim como reorganizações dentro da estrutura desta família que está se modificando (Johnson, 2005; Musito, 2001).

No caso de Bernardo, é interessante salientar que ele era o único responsável pelo sustento da casa. Dessa forma, a preocupação e a responsabilidade com a questão financeira estavam intensificadas para ele. Percebe-se nessa família uma divisão mais tradicional de funçôes, estando a esposa responsável pelo ambiente doméstico e o marido pela manutenção econômica. Esta divisão presente no casal confirma que o próprio ambiente intrafamiliar ainda mantém, muitas vezes, os estereótipos relativos às funções de gênero (Jablonski, 1999; Meler, 2000). Mesmo assim, Bernardo parece estar bastante identificado com a gravidez da esposa e faz críticas quanto às condiçôes oferecidas aos pais/homens pela estrutura de trabalho na atualidade. Segundo ele, a vida profissional não favorece espaço para conciliação com a vida familiar.

Provavelmente, por sua identificação com a esposa no momento da gravidez, Bernardo também foi sensível às manifestaçôes físicas desta vivência, destacando sensações relativas ao período gestacional em si, indo ao encontro do que afirmam Budur, Mathews e Mathews (2005), ao mencionarem que as reações do futuro pai podem ser tanto físicas como emocionais. Bernardo apontou aspectos tais como cansaço, sonolência, irritabilidade como decorrentes da gravidez da esposa, parecendo consciente das transformações pelas quais não só a mulher, mas também o homem, freqüentemente, passa neste período.

Outro aspecto interessante na dinâmica deste caso é a retomada feita por Bernardo de suas vivências enquanto filho. Seus relatos reforçam o que dizem Dalia (1999) e Schoppe-Sullivan (2004) sobre a importância que a relação que o homem teve com sua família de origem adquire no momento da vivência da paternidade. É comum que os valores e a educação recebidos sejam, muitas vezes, reativados e reavaliados. Bernardo retomou sua vivência infantil e adoles- 
cente e reavaliou a forma como seus pais lidaram com isso, ao pensar no futuro de seu filho.

CASO 3 - Carlos, 34 anos, cuja esposa encontrava-se no $8^{\circ}$ mês de gravidez. A passagem da conjugalidade para a parentalidade - Carlos mencionou que a gravidez representou uma maior estabilidade na relação e também uma maior sensação de continuidade da vida de casal: "como a gente não se casou com formalidades, eu acho que a gravidez contribuiu para ser uma relação estável, sólida, um casamento...";

Os sentimentos de "estar grávido" - Neste aspecto, Carlos falou das expectativas que tem de si mesmo nesse processo, de estar extremamente emocionado: "no mais estou ansioso que nasça para ver qual vai ser minha reação, porque eu tenho certeza que vou desmoronar quando nascer, vou cair em prantos...”.

Quanto a aspectos físicos ou psicológicos experimentados por ele durante a gravidez, disse que percebeu em si um incremento da sensibilidade: "mas é um período que eu senti que aumentou minha sensibilidade, por natureza já sou bem sensível para algumas coisas, mas teve momentos em que eu me senti muito mais sensível...”.

Carlos relatou "sentir-se grávido" e também incluído no processo gestacional de sua esposa: "eu acho que sim, para mim pelo menos eu tenho essa sensação, de não ser só a mãe, 'ah, a mãe tá grávida', até essa parte da sensibilidade que eu tava te falando acho que tem a ver com isso; não me sinto nem um pouco excluído, nenhum lugar, bem pelo contrário, não imaginava que fosse me sentir tão incluído, por exemplo, teve um dia que uns colegas compraram umas fraldas eu achei muito legal...".

Perspectiva de futuro em relação à paternidade - Carlos falou o quanto acredita na importância da proximidade na relação pai-filho para que a criança tenha um desenvolvimento saudável.

O entrevistado referiu-se à importância de ter uma família estruturada, comentando a respeito das modificaçôes que está fazendo em sua vida pessoal com a proximidade da chegada do seu filho: "cuidar para não ficar só trabalho, por exemplo, agora eu gostaria de estar estudando para um outro concurso, e eu penso que se estudasse agora, então já não curtiria tanto os primeiros tempos da criança...”. Ele também falou da perspectiva de ser pai como uma possibilidade de retomar aspectos da relação com seu pai, visto que tiveram pouca proximidade, pois seu pai faleceu quando ele ainda era muito jovem.

Ele acrescentou que sentia como se o momento estivesse passando demasiadamente rápido, relatando o desejo de estar o mais próximo possível, aproveitan- 
do e acompanhando de perto as mudanças da gravidez: "às vezes eu tenho a sensação de que é muito rápido, às vezes eu queria participar mais da gravidez no sentido de curtir mais mesmo...”.

Perspectiva em relação ao futuro do filho - O sujeito referiu ter certa preocupação a respeito dos cuidados iniciais com o bebê. Ele comentou que as mulheres têm maior habilidade que os homens em lidar com recém-nascidos. Explica que há uma criação diferenciada entre meninos e meninas. Carlos ilustrou essa vivência constatando que a primeira vez que ele teve contato com uma criança pequena foi há pouco tempo atrás, visto que quando criança não experimentou esse tipo de situação. Ele descreveu sua sensação: "estava cheio de medo, pois criança é uma coisa frágil”.

Vislumbrando um futuro mais distante, verbalizou que acredita que, se oferecer ao filho a continência de uma família estruturada, este poderá desenvolverse sem correr tantos perigos, como, por exemplo, o uso de drogas: "se a pessoa tá numa família, tá numa relação estruturada, pode até experimentar, mas não vai entrar”. Devido à consciência que tem sobre a sua responsabilidade, teme a educação que pode proporcionar ao filho, tem angústias, preocupa-se com a adolescência e quer encontrar na relação com o filho a medida adequada do limite necessário ao seu desenvolvimento.

\section{Análise Compreensiva do Caso 3:}

Neste caso, o pai entrevistado vivencia a vinda do filho como uma continuidade da vida do casal. Para Carlos, o filho também representa uma maneira de formalizar a relação com a esposa, já que não houve o casamento legal. Pode-se perceber que o bebê tem, desde já, psiquicamente, diversos significados para este pai, inclusive a possibilidade de resgate de uma proximidade que ele próprio não pôde vivenciar prolongadamente com o seu pai pelo falecimento precoce do mesmo.

Neste sentido, o que Carlos refere diz respeito à variedade de aspectos que se modificam na chegada de mais um membro na família, pois a passagem para a paternidade envolve também uma avaliação de si mesmo, de suas responsabilidades e prioridades, muitas vezes, abrindo a possibilidade para mudanças de valores e crenças, incluindo os valores da vida profissional (Johnson, 2005; Musito, 2001).

É interessante salientar que Carlos mostrou-se capaz de refletir sobre a possível origem do seu temor quanto à chegada do filho, sentindo-se menos preparado que a mãe e temendo não saber lidar com um bebê recém-nascido, devido às diferenças na criação de meninos e meninas. Indo ao encontro do que afirmam Fleck, Falcke e Hackner (2005), ele compreende que a incorporação da maternidade se dá desde os primórdios da infância, através de brincadeiras que estimulam esse cuidado. As 
meninas desde pequenas já brincam de bonecas, assim fantasiosamente exercem o papel materno, e os meninos não, caracterizando um maior preparo feminino para a parentalidade na visão do pai (Levandowski \& Piccinini, 2006).

Mesmo assim, Carlos tem o desejo de estar junto do filho, ser presente, e abdica de tarefas pessoais para tal. Talvez por esse desejo de participação ele de fato não se sinta de fora dessa relação. Pode-se pensar que, além de seu desejo de participação, a postura de sua esposa também tenha sido favorecedora de sua inclusão nesse processo. Sobre esse fenômeno, a mãe pode ter uma grande contribuição na relação do pai com o filho, uma vez que ela pode facilitar ou dificultar o vínculo pai-bebê (Anderson, 1996; Parke, 1996; Ridenti, 2001). Esse é um processo que se inicia já na gestação.

CASO 4 - Daniel, 35 anos, cuja mulher encontrava-se no $7^{\circ}$ mês de gravidez. A passagem da conjugalidade para a parentalidade - Daniel percebeu mudanças na relação conjugal a partir da gravidez. Ele deixou de pensar em duas pessoas para pensar sempre em três: "Mudou, pois agora a gente está pensando em três, e antes a gente só pensava por dois, agora a gente está pensando por três...”.

No entanto, disse não ter percebido outras mudanças: "no nosso relacionamento não mudou quase nada, claro, se torna um pouco mais sensível, então algumas brigas acontecem, até porque acho que o homem fica menos sensível, custa a mudar um pouco a atitude...". Neste sentido, disse ter percebido a importância de ele ser continente às necessidades e angústias da mulher nesse período: "é tu continuar sendo o amigo e o companheiro da tua mulher, saber que ela tá mais delicada, como eu te disse que ela fica bem mais delicada, compreender, e manter sempre a união...”.

Os sentimentos de "estar grávido" - Daniel falou do aumento de sua ansiedade, bem como do seu desejo de que a gravidez passe rápido. Referiu também que foi importante acompanhar os movimentos e o crescimento da barriga: "aumenta a ansiedade, agora no final tô mais ansioso que vai nascer...". Relatou que o que mais marcou durante a gravidez foi a sua necessidade de acompanhar a esposa, desde ir a exames até a preparação do ambiente físico.

No entanto, houve momentos em que pôde também descrever situações em que se sentia "de fora", referindo a interação da esposa com a sogra. Justificava estas situações através das diferenças de gênero: “é, às vezes é mãe e filha que começam a falar, vou comprar isso, vou comprar aquilo, então a gente fica meio de lado, é coisa de mulher...”.

Perspectiva de futuro em relação à paternidade - Daniel descreveu que deseja que esse período gestacional passe o mais rápido possível para que chegue o mo- 
mento do parto para de fato sentir seu filho como real: "quero que nasça rapidinho para que eu possa abraçar, beijar...”.

Ao ser perguntado sobre suas possíveis preocupaçôes neste processo, Daniel referiu que é preciso primeiro ter uma condição econômica estável, e assim associou suas preocupaçôes com a possibilidade de prover e poder dar o melhor para o filho. No que tange a essa questão econômica, ele não se responsabilizou unicamente por essa função, pois, no caso de Daniel e sua esposa, os dois trabalham igualmente e a preocupação financeira se divide.

Perspectiva em relação ao futuro do filho - Neste momento, Daniel descreveu o medo de uma possível doença quando a criança nascer: "medo que nasça com alguma doença, mas acho que não vai, o Dr. já fez os exames e já deu tudo normal...”.

Ainda ao que se relaciona ao futuro do filho, Daniel associou imediatamente o temor frente à inserção do filho no mundo de hoje, devido à violência: "a gente vai ter um filho, vai colocar ele no mundo, mas não sabe realmente o que pode acontecer...”.

\section{Análise Compreensiva do Caso 4:}

Já no início da entrevista, o sujeito descreveu como estava vivenciando o processo gestacional: "foi muito bom, e a melhor coisa foi o dia em que eu fiquei sabendo que eu ia ser pai”. A partir dessa verbalização, foi possível perceber o sentimento dele relacionado à gravidez como um período necessário para ajudar no processo de conscientização da paternidade. O próprio tempo verbal utilizado por ele, "ia ser pai", demonstra a conotação que atribui à gravidez, ou seja, significa que, quando nascer a criança, finalmente, ele poderá exercer a paternidade. Este aspecto vai ao encontro do que apontam Piccinini, Silva e Gonçalves (2004), de que muitos pais apresentam dificuldades quanto ao envolvimento com seu filho durante a gravidez, parecendo não percebê-lo como real e, dessa forma, apresentando uma baixa ligação emocional com a gestação em si.

Ao falar sobre o futuro do seu filho, ele reflete sobre os riscos e perigos do mundo a que, por melhor que seja a educação recebida em casa, seu filho estará exposto. Daniel percebe que não poderá ser um "super-herói”, capaz de impedir seu filho de viver em um mundo que, mesmo com toda sua proteção, tem uma série de perigos, de toda a natureza.

O sujeito mostrou vivenciar a gravidez da esposa sendo continente e afetivo. Assumiu um papel e uma função de apoio incondicional à esposa, sentindo que sua subjetividade e suas angústias deveriam estar em segundo plano. Essa é uma atitude bastante comum em muitos homens que não se permitem dividir suas ansiedades e seus medos neste período por sentirem a necessidade e a obrigação de protegerem a mãe/esposa nesse processo, em detrimento de seus próprios temores (O’Leary \& Thorwick, 2006). 
CASO 5 - Eduardo, 34 anos, cuja mulher encontrava-se no $8^{\circ}$ mês do período gestacional.

A passagem da conjugalidade para a parentalidade - Eduardo passou a falar das alteraçõoes ocorridas em sua relação conjugal, a partir das transformações da esposa e da necessidade de se adaptar às mesmas: "o que mudou no nosso relacionamento é que a mulher se transforma, fica mais sonolenta, fica com fome em períodos de menores espaços de tempo, notei grande diferença de sensibilidade...”. Diante das modificações da esposa, Eduardo pareceu tender à adaptação, satisfazendo a mulher em seus desejos.

Quando questionado sobre o que se modificou no seu casamento, ele respondeu que foi uma maior consolidação da sua relação com a esposa: "ah, eu acho que o que mais me chama atenção é nosso sentimento, a gente é um casal bem feliz, mas acho que fortificou nosso relacionamento...”.

Os sentimentos de "estar grávido" - Eduardo mencionou perceber também em si algumas transformações em alguns aspectos, tais como o aumento da sensibilidade e algumas alterações físicas: "tu fica mais sensível, tu nota mais as coisas, começa a analisar a coisa mais para o lado sentimental, isso aí...; a coisa que eu notei é que me arrebentou uma dor de dente do nada... quando minha avó teve grávida de um tio meu, meu avô morreu de dor de dente e não tinha nada... Eu tive isso durante uma semana. Fui no dentista e não tinha nada nos dentes!...”.

Mais adiante, ao ser questionado diretamente se se sentia "grávido", ele resume essa questão dizendo: "é, psicologicamente me sinto sim, tenho necessidade de conversar com o próprio feto". Por outro lado afirma: "não me sinto no sentido fisiológico, né?”, apesar de identificar sintomas físicos inexplicados em si, como mencionado anteriormente.

Perspectiva de futuro em relação à paternidade - Eduardo descreveu seu desejo de transmitir o maior amor possível ao filho. Neste sentido, passou a falar de recordações da sua infância, expressando o desejo de proporcionar, no mínimo, o mesmo carinho que recebeu dos seus pais: "claro que a gente pensa em dar bastante amor e carinho e tal, só quero que no mínimo tenha o mesmo ou mais amor do que eu tive dos meus pais, é isso que a gente deseja e quer passar...”.

Perspectiva em relação ao futuro do filho - Eduardo mencionou o seu temor e a sua apreensão de deparar-se com uma malformação: "preocupações de a criança nascer com algum defeito, com alguma coisa assim, a gente fica apreensivo...”.

Ele falou ainda sobre a adolescência, que é, dentre suas preocupaçôes com o futuro do filho, a mais marcante. Para ele, essa etapa desenvolvimental é perigosa e ele teme que o filho repita situações que ele mesmo já viveu nesse período: “em 
relação ao futuro eu tenho muito medo, porque aí que vem o caso da gente fazer a comparação de como eu era...”.

Por outro lado, deseja que o filho repita a sua vivência infantil, a qual recorda como um período feliz de sua vida, no qual relata ter sido muito amado por seus pais. Nesse sentido, é visível que a expectativa de ser pai também remete Eduardo às suas vivências anteriores, enquanto filho em sua família de origem.

\section{Análise Compreensiva do Caso 5:}

Eduardo, ao falar de sua relação conjugal durante a gestação, mencionou uma maior aproximação do casal, uma maior união e fortalecimento do vínculo conjugal. Essa afirmação vai ao encontro do que postula Bronfenbrenner (1996), de que um filho pode contribuir para a aproximação do casal, já que o relacionamento marido-mulher está vinculado à unidade mãe-bebê, na qual essa associação entre estabilidade conjugal e vinculação do pai com o bebê já se percebe desde a gravidez (Schoppe-Sullivan, 2004).

Sobre seus temores, Eduardo fala de um sentimento que é compartilhado pela maioria dos pais nesse período: a malformação fetal (Piccinini, Silva \& Gonçalves, 2004). A etapa desenvolvimental do adolescer também aparece como um temor. Durante a entrevista, lembrou que quando ele viveu essa fase arriscava-se e colocava-se em situaçôes de perigo para se divertir. Eduardo faz o movimento que Bowen (1991) descreve como o receio de transmissão de níveis de imaturidade para a próxima geração com a volta ao passado na busca de modelos. Nesse retrocesso às suas experiências, ele é acometido de recordações que causam medo; assim, espera que o filho não o re-edite.

Ao falar de seus sentimentos frente à gravidez, Eduardo referiu a percepção de alguma alteração física, como dor de dente. No entanto, Eduardo se contradiz, ao falar em outros momentos que não sofreu nenhuma mudança, explicitando sua ambivalência diante de suas vivências nesse processo.

\section{Análise horizontal dos casos e consideraçôes finais}

A partir da experiência relatada nesses cinco casos, foi possível averiguar que a vivência da gravidez à luz da perspectiva paterna é um fenômeno complexo no qual estão presentes aspectos do macro e do micro-sistema que compõem a realidade de cada sujeito, de forma interdependente.

As transformações na relação conjugal apareceram com grande relevância dentre os aspectos destacados pelos pais. Foi possível constatar todo um movimento de reorganização das famílias, desencadeando um processo de reestruturação 
e readaptação para a inclusão de um novo membro, redimensionando valores, expectativas e prioridades.

Independente do planejamento da gravidez, foi possível observar que todos os participantes imaginavam o filho, predominantemente, em uma perspectiva futura, posterior ao nascimento. Nesse movimento de remeterem-se ao tempo futuro e imaginarem seus filhos em diferentes etapas de seu desenvolvimento, a adolescência foi a etapa mais citada, provavelmente por tratar-se de um dos períodos mais complexos do ciclo de vida de muitos indivíduos. Os participantes que tiveram uma adolescência de certa forma turbulenta e até traumática temem essa etapa desenvolvimental, frente à possibilidade de reedição desse período na vida do filho.

Outro aspecto importante foi que três dos cinco participantes também referiram uma sobrecarga por serem os principais provedores da família. O fato de os homens voltarem-se mais para o trabalho quando a esposa está grávida expressa a tendência histórica de que o sustento econômico seja uma tarefa desempenhada predominantemente pelo homem. Devido à consolidação desse aspecto na dinâmica familiar há muitos anos, nem sempre os homens questionam e criticam tal incumbência. No entanto, no caso de Bernardo, ele refere esta desigualdade, adotando uma postura crítica diante de como a sociedade e suas leis ainda estão estruturadas na perspectiva de um papel secundário para os pais/homens.

Neste sentido, pôde-se constatar que todos os sujeitos manifestaram o desejo de uma maior proximidade e participação durante a gestação e o desenvolvimento dos filhos. Entretanto, o relato de momentos de exclusão neste período também esteve presente em suas falas, com distintas variações de intensidade. Em contrapartida, alguns pais parecem justificar essa exclusão trazendo à tona questôes relativas às diferenças de gênero. Eles mencionam uma maior facilidade das mulheres no cuidado com os filhos, descrevendo uma espécie de habilidade natural feminina. No entanto, Carlos questionou o aspecto "natural" atribuído a esse processo, o que na visão dele é decorrente das questões culturais da nossa sociedade.

Por outro lado, mesmo os participantes que esperavam o parto acontecer para sentirem-se pais ou para concretizarem a paternidade encontram formas de participar e fazer parte deste processo, revelando que este momento encontra-se cada vez menos restrito ao universo feminino. Podem, por exemplo, estar envolvidos através do suporte à esposa e do atendimento às suas necessidades, como no caso de Daniel, colocando em segundo plano suas próprias dúvidas, suas necessidades e seus temores.

Os casos descritos nesse estudo certamente não abrangem todas as vivências possíveis de futuros pais de primogênitos. O cenário atual compõe-se pela coexistência de modelos de relação, desde aqueles marcados pelas diferenças de gênero, 
que afastam o homem da vivência desse processo, até aqueles nos quais os homens demonstram um envolvimento intenso nesta experiência. No entanto, mesmo sem o viés comum de um modelo, ou protótipo específico, os entrevistados mostraram uma questão comum: a carência de serem ouvidos, expressa pela necessidade de falar e pela disposição em participar da pesquisa.

O que há de maior relevância neste movimento é a possibilidade que os pais dos dias de hoje estão tendo de refletir a paternidade, questionando antigos valores e definições, abrindo a possibilidade de uma nova concepção e uma nova forma de vivenciar este papel. Ser pai atualmente é, certamente, caminhar por um terreno desconhecido, antes e depois do nascimento dos filhos. As referências passadas não são mais suficientes para dar conta das demandas da paternidade na atualidade. Reinventar e redefinir o lugar do pai na família e na sociedade é, certamente, um dos grandes desafios dos homens e mulheres da contemporaneidade.

\section{REFERÊNCIAS BIBLIOGRÁFICAS}

Anderson, A. M. (1996). Factors influencing the father-infant relationship. Journal of Family Nursing, 2 (3), 306-324.

Andrews, A. B.; Luckey, I.; Bolden, E.; Whiting-Fickling, J. \& Lind, K. A. (2004). Public perceptions about father involvement. Journal of Family Issues, 25, 603-633.

Badinter, E. (1986). Um é o outro. Rio de Janeiro: Imago.

Bolsan, N.; Gale, F. \& Dudley, M. (2004). Time to father. Social Work in Health Care, 39, 67-88.

Bornholdt, E. (2006). Inicio de la Interacción padre-bebé: perspectiva histórica, politica, social y académica. Tesis de Doctorado. Universidad del Salvador, Buenos Aires: Argentina.

Bowen, M. (1991). De la familia al individuo: la diferenciación del si mismo en el sistema familiar. Buenos Aires: Paidós.

Bronfenbrenner, U. (1996). A ecologia do desenvolvimento humano: experimentos naturais e planejados. Porto Alegre: Artes Médicas.

Budur, K.; Mathews, M. \& Mathews, M. (2005). Couvade Syndrome Equivalent? Psychosomatics: Journal as Consultation Liaison Psychiatry, 46, 71-72.

Burdon, B. (1998). Envolvendo os homens na vida familiar: se eles podem fazê-lo por que não o fazem? Em Silveira, P. (Org.). O exercício da paternidade (pp. 81-90). Porto Alegre: Artes Médicas.

Carter, B. \& McGoldrick, M. (1995). As mudanças no ciclo de vida familiar: uma estrutura para a terapia familiar. Porto Alegre: Artes Médicas. 
Chorvat, I. (2006). Towards some aspects of childcare and housework from the gender perspective. Sociologia, 38, 31-48.

Costa, G. P. (2000). A cena conjugal. Porto Alegre: Artmed.

Dalia, J. M. (1999). The effects of pregnancy on the marital satisfaction of expectant fathers: a program design for first trimester changes. Dissertation Abstracts International: Section B: The Sciences and Engineering, 60, 1848.

De Neuter, P. (2001). Becoming a father nowdays: difficulties and dilemmas. Pensée, 327, 59-76.

Diehl, A. (2002). O homem e a nova mulher: novos padróes sexuais de conjugalidade. Em Wagner, A. (Org.). Familia em cena: tramas, dramas e transformaçôes (pp. 135-158). Rio de Janeiro: Vozes.

Dudova, R. (2006). Old obligations in the modern world: the father as provider before and after divorce. Sociologicky Casopis-Czech Sociological Review, 42, 573-590.

Fleck, A. C. \& Wagner, A. (2003). A mulher como principal provedora do sustento econômico familiar. Psicologia em Estudo, 8, 31-38.

Fleck, A. C.; Falcke, D. \& Hackner, I. T. (2005). Crescendo menino ou menina: a transmissão dos papéis de gênero na família. Em Wagner, A. (Org.). Como se perpetua a familia?: a transmissão dos modelos familiares (pp.107-121). Porto Alegre: EDIPUCRS.

Freitas, W. M. F.; Coelho, E. A. C. \& Silva, A. T. C. (2007). Sentir-se pai: a vivência masculina sob o olhar de gênero. Cadernos de Saúde Pública, 23, 137-145.

Gracia, E. \& Musito, G. (2000). Psicologia Social de la Familia. Barcelona: Paidós.

Hijjawi, G. R. (2005). Father involvement in diverse families at one-year follow-up. Dissertation Abstracts International: Section B: The Sciences and Engineering, 66, 2877.

Hurstel, F. (2001). Thinking nowdays fatherhood. Pensée, 327, 47-57.

Jablonski, B. (1999). Identidade masculina e o exercício da paternidade: de onde viemos e para onde vamos. Em Féres-Carneiro, T. (Org.). Casal e Família: entre a tradição e a transformação (pp. 55-69). Rio de Janeiro: Nau.

Johnson, M. K. (2005). Family roles and work values: processes of selection and change. Journal of Marriage and Family, 67, 352-369.

Levandowski, D. C. \& Piccinini, C. A. (2006) Expectativas e sentimentos em relação à paternidade entre adolescentes e adultos. Psicologia: Teoria e Pesquisa, 22, 17-27.

Lewis, C. \& Lamb, M. E. (2003). Fathers influence on children's development: the evidence from two-parent families. European Journal of Psychology of Education, 18, 211-228.

Meler, I. (2000). La masculinidad. Diversidad y similitudes entre los grupos humanos. Em Burin, M. \& Meler, I. (orgs.). Varones: género y subjetividad masculina (pp. 71-121). Buenos Aires: Paidós.

Moraes, R. (1999). Análise de conteúdo. Educação, 37, 7-32.

Musito, G. (2001). La familia y la educación. Barcelona: Octaedro.

Olabuénaga, J. (1996). Metodología de la investigación cualitativa. Bilbao: Universidad de Deusto. 
O’Leary, J \& Thorwick, C. (2006). Fathers' perspectives during pregnancy, postperinatal loss. Journal of Obstetric Gynecologic and Neonatal Nursing, 35, 78-86.

Pacey, S. (2004). Couples and the first baby: responding to new parents' sexual and relationship problems. Sexual and Relationship Therapy, 19, 223-246.

Parke, R. (1996). Fatherhood. Cambridge, Massachussets: Harvard University Press. (1998). El papel del padre. Madrid: Morata.

Piccinini, C. A.; Silva, M. R. \& Gonçalves, T. R. (2004). Father's involvement during the gestation. Psicologia: Reflexão e Crítica, 17, 303-314.

Ridenti, U. S. G. (2001). Paternidades e masculinidades em contextos diversos. Revista Estudos Feministas, 9, 632-633.

Rodriguez, R. G. (2004). Measures of anxiety, stress, marital satisfaction and depression among first time expectant fathers living in a rural community: an antepartum and postpartum study. Dissertation Abstracts International: Section B: The Sciences and Engineering, 64, 6009.

Schoppe-Sullivan, S. J. (2004). The transition to coparenthood: influences on the development of the parenting partnership. Dissertation Abstracts International: Section B: The Sciences and Engineering, 64, 4088.

Shapiro, A. (2005). Examining relationships between the marriage, mother-father-baby interactions and infant emotion regulation. Dissertation Abstracts International: Section B: The Sciences and Engineering, 65, 3750.

Stake, R. (1994). Case Studies. Em Denzin, N. Handbook of Qualitative Research (pp. 435-454). London: Sage.

Staudt, A. C. P. (2007). Novos tempos, novos pais? O ser pai na contemporaneidade. Dissertação de Mestrado, Departamento de Psicologia, Pontifícia Universidade Católica do Rio Grande do Sul.

Trindade, Z. A. \& Menandro, M. C. S. (2002). Pais adolescentes: vivência e significação. Estudos de Psicologia (Natal), 7, 15-23.

Wagner, A. \& Grzybowski, L. S. (2003). Uma andorinha sozinha não faz verão? A mulher divorciada e a monoparentalidade familiar. Psicologia Clínica, 15, 13-30.

Wagner, A.; Hartmann, F. V.; Oliveira, H. B. \& Ribeiro, K. M. (1999). Configuração familiar e gênero: um estudo com adolescentes sobre família, casamento, separação e projetos vitais. Psicologia Clínica, 10, 99-112.

Zimmermann, A.; Zimmermann, H.; Zimmermann, J.; Tatsch, F. \& Santos, C. (2001). Gestação, parto e puerpério. Em Eizirik, C.; Kapczinski, K. \& Bassols, A. (Orgs.). O ciclo da vida humana: uma perspectiva psicodinâmica (pp. 29-40). São Paulo: Artmed.

Recebido em 23 de abril de 2007

Aceito para publicação em 9 de agosto de 2007 